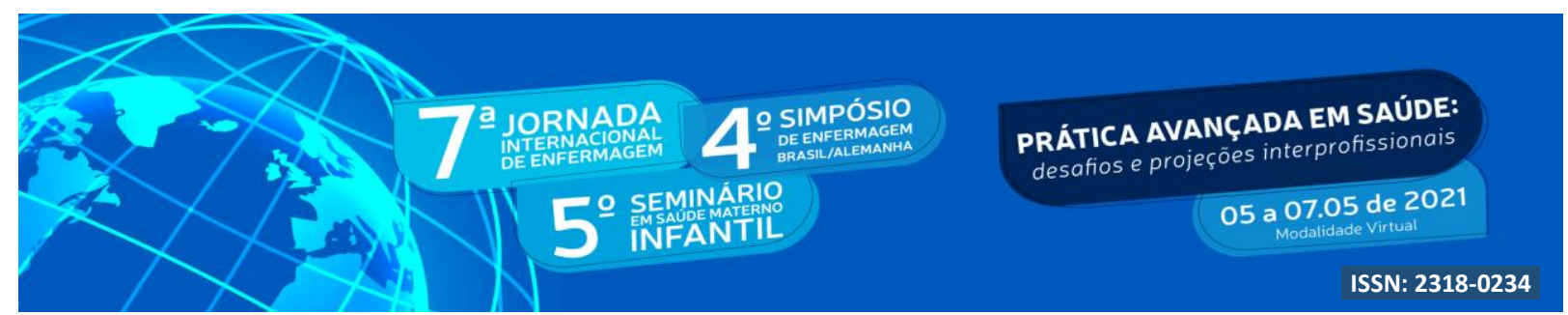

\title{
ALEITAMENTO MATERNO DE RECÉM-NASCIDOS EM TEMPOS DE PANDEMIA: REFLEXÕES DE ESTUDANTES DE ENFERMAGEM ${ }^{1}$
}

\author{
Isadora Balconi²; Maria Denise Schimith ${ }^{3}$; Anna Júlia Pacheco Alves ${ }^{4}$; Adriélli Idalgo Balconi ${ }^{5}$; \\ Isadora de Vasconcelos Amaral ${ }^{6}$; Daiana Cristina Wickert ${ }^{7}$
}

\begin{abstract}
RESUMO
O presente estudo objetiva refletir sobre as evidências científicas acerca do aleitamento materno de recém-nascidos no contexto da infecção por SARS-CoV-2. Trata-se de um estudo descritivo, do tipo teórico-reflexivo, com abordagem qualitativa, que possibilitou a análise de dados e materiais teóricos, a partir da busca na Biblioteca Virtual em Saúde. Os resultados revelam discrepâncias entre as recomendações de alguns países. Todavia, majoritariamente, aconselha-se manter o aleitamento, pois seus benefícios superam as incertezas presentes em relação à transmissão vertical do vírus, desde que seguidas as medidas de prevenção e os cuidados necessários, como lavar as mãos antes de tocar o bebê ou retirar o leite materno, utilizar máscara facial, entre outras. Por fim, mostra-se imprescindível a atuação da Enfermagem no cuidado e na educação em saúde para que a amamentação seja vantajosa para a mãe e para o bebê, apesar das incertezas advindas com a pandemia da COVID-19.
\end{abstract}

Palavras-chave: Aleitamento Materno; Assistência à Saúde; Enfermagem; Enfermagem MaternoInfantil; Nutrição do Lactente;

\begin{abstract}
This study aims to reflect on the scientific evidence about breastfeeding newborns in the context of SARS-CoV-2 infection. This is a descriptive, theoretical-reflective study, with a qualitative approach, which allowed the analysis of data and theoretical materials, from the search in the Virtual Health Library. The results reveal discrepancies between the recommendations of some countries. However, mostly, it is advisable to continue breastfeeding, because its benefits overcome the uncertainties present in relation to the vertical transmission of the virus, as long as the necessary prevention and necessary virus, as long as the necessary prevention and necessary care, such as to wash hands before touching the baby or expressing breast milk, using a face mask, among others. Finally, the role of Nursing in health care and education is essential for breastfeeding to be advantageous for the mother and baby, despite the uncertainties arising from the COVID-19.
\end{abstract}

\footnotetext{
${ }^{1}$ Estudo vinculado ao Grupo de Pesquisa Cuidado, Saúde e Enfermagem: Políticas Públicas e Práticas de Cuidado nos diversos cenários de Atenção à Saúde (PraCCeS) da Universidade Federal de Santa Maria (UFSM)/ Iniciação Científica.

${ }^{2}$ Estudante do Curso de Enfermagem. Universidade Federal de Santa Maria (UFSM). Bolsista do Programa de Educação Tutorial - PET Enfermagem. E-mail: isadorapbalconi@gmail.com

${ }^{3}$ Orientadora. Enfermeira. Professora Adjunta da UFSM. E-mail: ma.denise2011@gmail.com

${ }^{4}$ Estudante do Curso de Enfermagem. UFSM. Bolsista do Programa de Educação Tutorial - PET Enfermagem.

E-mail: anna.lilo2000@gmail.com

${ }^{5}$ Estudante do Curso de Enfermagem. Faculdade Integrada de Santa Maria (FISMA). E-mail: adriidalgobalconi@gmail.com

${ }^{6}$ Estudante do Curso de Enfermagem. FISMA. E-mail: amaralvasconcelosisadora@gmail.com

${ }^{7}$ Mestranda do Programa de Pós-graduação em Enfermagem.UFSM. E-mail: daianacristinaw@gmail.com
} 


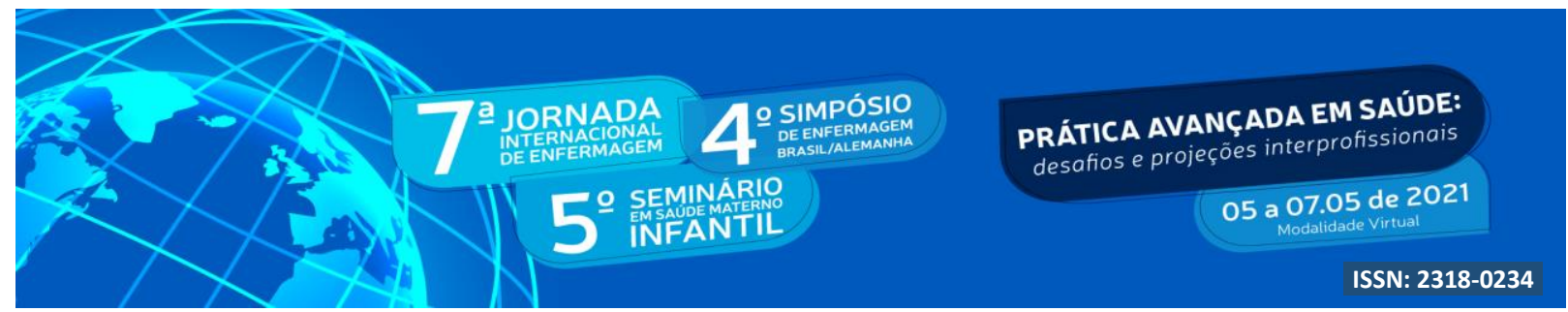

Key words: Delivery of Health Care; Breast Feeding; Infant Nutrition; Maternal-Child Nursing; Nursing;

\section{INTRODUÇÃO}

No dia 31 de dezembro de 2019, a cidade de Wuhan, localizada na China, vivenciou uma epidemia desconhecida, causada por um vírus denominado de Severe Acute Respiratory Syndrome Coronavirus 2 (SARS-CoV-2), responsável pela doença altamente infecciosa Coronavirus Disease 2019 (COVID-19). Devido à alta transmissão e incidência global, a Organização Mundial da Saúde (OMS), em 11 de março de 2020, anunciou uma pandemia. Esta pode ser transmitida, por meio de objetos ou superfícies contaminadas, tosse, espirro, gotículas de saliva, aerossóis e toque do aperto de mão contaminada (BRASIL, 2020a).

De acordo com a OMS, aproximadamente $80 \%$ dos pacientes com Covid-19 podem ser assintomáticos ou oligossintomáticos e cerca de $20 \%$ dos casos, requer atendimento hospitalar por complicações graves. Os sinais podem variar de um resfriado a uma Síndrome Gripal (SG), sendo os sintomas mais comuns, tosse, febre, coriza, dor de garganta, dificuldade para respirar, anosmia, ageusia, distúrbios gastrointestinais, astenia, hiporexia e dispnéia (BRASIL, 2020a).

Diferentemente dos adultos, a infecção por COVID-19 detém menor índice em recémnascidos. Contudo, torna-se essencial atentar aos sinais e sintomas, como dispneia e taquipneia, hipertermia ou hipotermia, taquicardia, êmese, sintomas gastrointestinais e trombocitopenia. Por outro lado, as crianças diagnosticadas com SARS-Cov-2 apresentam predominantemente febre baixa e tosse, com alguns sintomas gastrointestinais associados, prurido nasal, obstrução nasal, odinofasia e coriza (BRASIL, 2020b).

Frente ao contexto, o Ministério da Saúde (MS) argumenta que até o momento, não há validação científica que comprove a transmissão do coronavírus por meio da amamentação. Assim, considerando os benefícios para a qualidade de vida do recém-nascido (RN), aconselha-se que a lactação seja preservada mesmo em caso de infecção pelo SARS-CoV-2 (BRASIL, 2020c).

Sob esse viés, o MS implantou medidas de prevenção e higiene, a fim de tornar o aleitamento materno (AM) seguro e eficaz. 


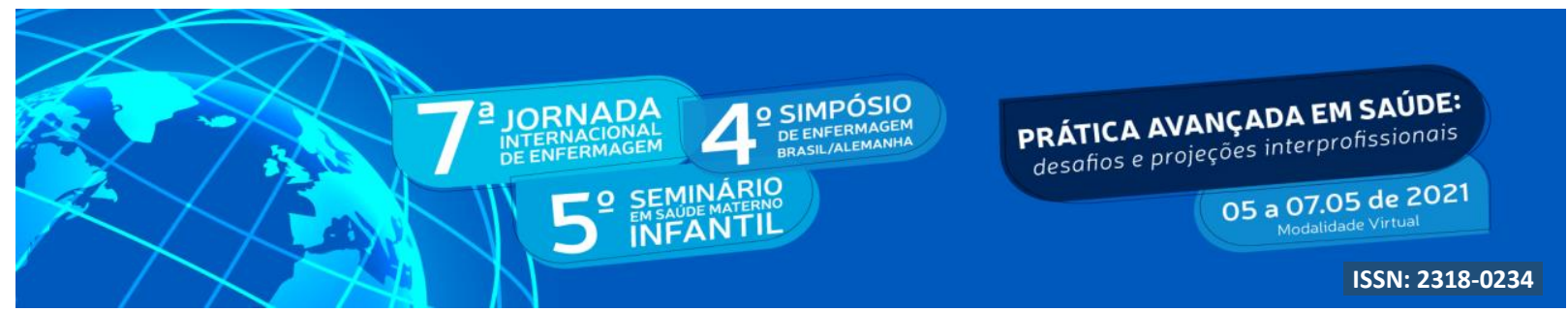

Sendo assim, a lactante infectada deve lavar as mãos antes de tocar o bebê ou retirar o leite materno, utilizar máscara facial e evitar tossir ou falar durante as mamadas (BRASIL, 2020c). Somado a isso, é imprescindível que a mãe ao oferecer o leite materno ao RN seja instruída pelo profissional de saúde.

Um estudo realizado pela Universidade Federal do Amazonas comparou dados referente ao número de mortes por COVID-19 em Manaus, no ano de 2020. A pesquisa constatou que bebês com menos de um ano, portadores de outras doenças, apresentam uma probabilidade de óbito de 19,2\%, taxa considerada alevada, se comparados com pacientes de 1 a 19 anos, sendo os índices de 1 a 4 anos 3,3\%, 10 a 14 anos 5,6\% e 15 a 19 anos 8,5\%. Já crianças que não possuem nenhuma patologia associada, a probabilidade cai drasticamente, em bebês com menos de um ano de idade $1,9 \%$ e de 1 a 19 anos menos de $1 \%$ (UNIVERSIDADE FEDERAL DO AMAZONAS, 2021).

Cabe destacar que alguns países como a China e Portugal, contraindicam a amamentação durante a infecção pela COVID-19, enquanto países como o Brasil, incentivam, desde que a mãe esteja em condições clínicas adequadas e este seja o seu desejo. Devido às mudanças constantes no que se refere à COVID-19 e às medidas de cuidados, mostra-se necessário a cooperação em nível mundial com atualizações acerca da temática, especialmente por parte dos profissionais de saúde, com o intuito de garantir assistência segura e de qualidade. Logo, faz-se evidente a importância de estudos sobre o assunto e reflexões sobre as evidências atuais em diferentes contextos mundiais.

\section{OBJETIVOS}

Refletir sobre as evidências científicas acerca do aleitamento materno de recémnascidos no contexto da infecção por SARS-CoV-2.

\section{METODOLOGIA}

Trata-se de um estudo descritivo, do tipo teórico-reflexivo, oriundo da análise de publicações selecionadas nas bases de dados Literatura Latino Americana e do Caribe de 


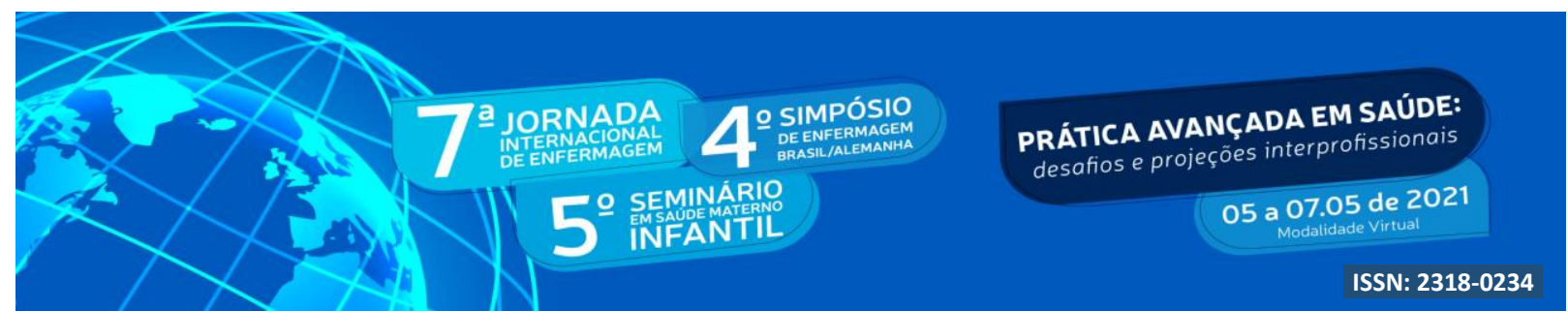

Informações em Ciências da Saúde (LILACS), Base de Dados de Enfermagem (BDENF) e da Biblioteca Médica Nacional (CUMED), via Portal Regional da Biblioteca Virtual em Saúde (BVS).

Para a realização desse estudo utilizou-se o método teórico-reflexivo, com abordagem qualitativa, o qual possibilitou a análise de dados e materiais teóricos, a partir da busca bibliográfica. Isso porque esse método potencializa o desenvolvimento de competências imprescindíveis para a formação do profissional de enfermagem, como a autonomia, o protagonismo e a reflexão (LIMA, et. al., 2014; NETTO; SILVA; RUA, 2018).

Realizou-se a busca no período de março de 2021, por estudantes da graduação e pósgraduação em enfermagem. Para a estratégia de busca, foram utilizados o descritor "aleitamento materno" e o sinônimo "COVID-19", extraídos dos Descritores em Ciências da Saúde (DeCS) e, após a testagem nas bases de dados, resultou na estratégia de alta sensibilidade: (aleitamento materno) AND (COVID-19). Os critérios de inclusão foram: estudos disponíveis na íntegra on-line, gratuitamente, nos idiomas português, inglês ou espanhol, que estivessem de acordo com o objetivo da pesquisa, sem recorte temporal.

A busca resultou em 21 estudos, destes 15 oriundos da LILACS, 05 da BDENF e 01 da CUMED. Nesse sentido, os duplicados foram considerados apenas uma vez, reduzindo para 14 estudos, e após aplicar os critérios de inclusão, restaram 12 estudos, que foram apreciados mediante a leitura na íntegra.

\section{RESULTADOS E DISCUSSÃO}

A partir da análise e síntese dos resultados, embora a OMS recomende a amamentação mesmo em mulheres infectadas pela COVID-19, com os cuidados como uso de máscara, lavagem das mãos a cada mamada e após, e a limpeza de utensílios, para impedir a contaminação do recém-nascido $(\mathrm{RN})$, alguns especialistas chineses desestimularam o AM em mães suspeitas ou infectadas, devido aos riscos de transmissão vertical do vírus, recomendando um período de isolamento e, posteriormente, o retorno dessa prática. De maneira análoga, Portugal, recomendou a extração com bomba, tendo em vista o mesmo contexto materno. Além disso, nos Estados Unidos, centros especializados vão ao encontro 


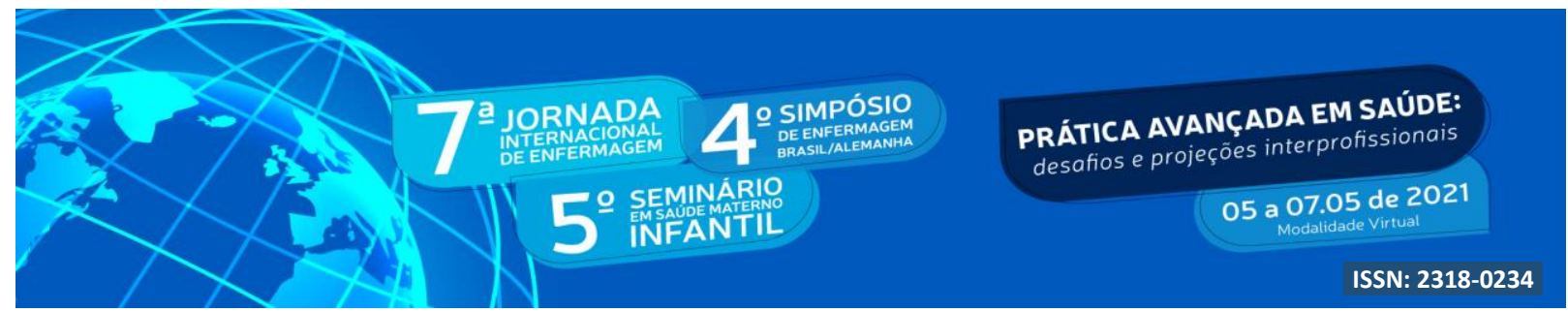

dos mesmos posicionamentos, mas destacam que a continuidade da amamentação deve ser uma escolha materna junto à equipe multiprofissional que a assiste. Em relação à Itália, esta recomenda o AM apenas para mães assintomáticas ou com sintomas leves (MOCELIN; PRIMO; LAIGNIER, 2020).

No que se refere ao leite materno, sabe-se da sua relevância no crescimento e desenvolvimento cognitivo e emocional do RN. Possui características imunológicas que contribuem para o controle de infecções e doenças, sendo o método mais econômico de alimentação (PRATA et al., 2020; CALI; KREDS; CARVALHO, 2020; CONTRERAS et al., 2020), demonstrando a importância do AM para o bem-estar materno-infantil.

No entanto, durante a pandemia da COVID-19, em muitos casos, foi realizado o afastamento das mães infectadas, interrompendo a amamentação. Nesse contexto, uma estratégia para restabelecer a prática foi a relactação, que consiste em restabelecer a produção de leite materno, por meio da promoção de um ambiente tranquilo para a mãe e da indução de ocitocina e prolactina (DANTAS et al., 2020; PRATA et al., 2020).

Convém salientar, que os profissionais da saúde, que atuam no âmbito da atenção primária à saúde, sobretudo a equipe de enfermagem, possuem protagonismo no acompanhamento das puérperas, constituindo uma importante rede de apoio à mulher e à família para a manutenção da amamentação. Dessa forma, mostra-se imprescindível a adequação dos serviços assistenciais diante dos desafios advindos pela pandemia, como o uso dos meios de comunicação para a continuidade do cuidado.

Hodiernamente, a maior preocupação com a amamentação encontra-se na possibilidade de transmissão do vírus, por meio de gotículas da mãe para o RN (MASCARENHAS et al., 2020; FILHO; SANTOS; JUNIOR, 2020). Isso porque em relação à transmissão vertical do vírus, não há evidências que a confirmem, ainda que foram detectadas algumas alterações placentárias advindas de processos inflamatórios que podem estar relacionados à COVID-19. No entanto, não se verificou sua presença em amostras de líquido amniótico, cordão umbilical, swab da orofaringe de neonatos e no leite materno (LIMA et al., 2020).

Sendo assim, conhecendo todos os benefícios do leite materno e as dificuldades econômicas intensificadas pela pandemia, o AM contribui para a segurança alimentar do 


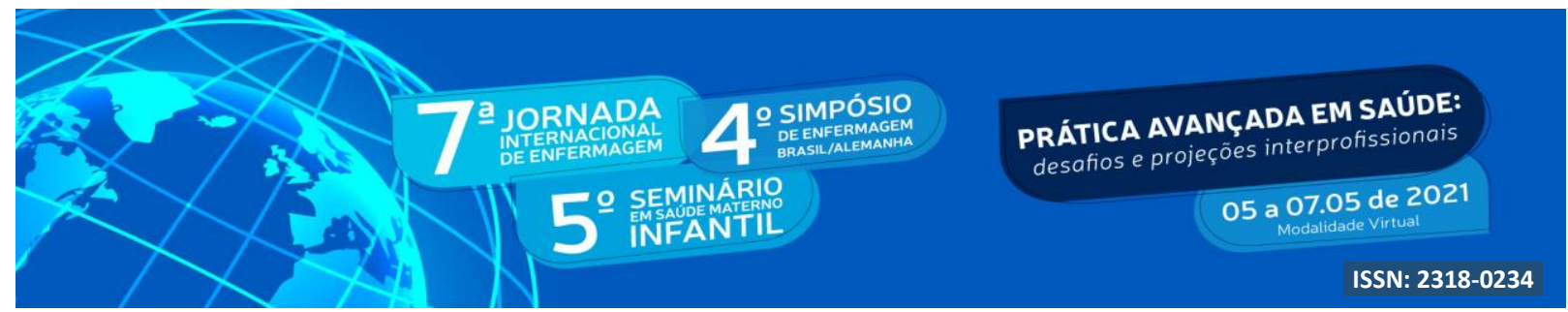

bebê, vínculo afetivo e fortalecimento do sistema imunológico, prevenção do sobrepeso, obesidade, doenças alérgicas, crônicas e infecciosas, além das contribuições à saúde materna (CALI; KREDS; CARVALHO, 2020; DANTAS et al., 2020).

Ao contrário dos países supracitados, a Espanha, ainda que no início da pandemia não tenha incentivado o AM pela insuficiência de informações, assim como o Brasil e França, recomenda este ato, devido aos benefícios para mãe-filho superarem quaisquer riscos de potenciais transmissão da COVID-19, como a proteção imunológica do RN, devendo-se estimular as mulheres a fazê-lo. Ademais, com base nas evidências científicas disponíveis, o MS, considerando as vantagens do AM para a saúde do binômio e a inexistência de contraindicações, recomenda que esta seja mantida em mulheres com COVID-19. Todavia, convém salientar que a mulher e a criança devem estar em condições clínicas propícias e sigam as recomendações de higienização e prevenção da OMS (MOCELIN; PRIMO; LAIGNIER, 2020; BAGLÁN-BOBADILLA, 2020; LÓPEZ et al., 2020; BRASIL, 2020d; CALI; KREDS; CARVALHO, 2020).

Pesquisas realizadas com gestantes no terceiro trimestre, a partir da análise do leite materno, constatou-se a presença de SARS-CoV-2. Todas apresentavam sintomas de doença respiratória aguda e febre, com indicativas de pneumonia por COVID-19. No entanto, após os partos, sobretudo cesárea, foram coletadas amostras biológicas do trato respiratório e tecidos placentários, os quais apresentaram resultados negativos para o vírus. Ademais, nesse período, as amostras de leite materno foram negativas também. Todavia, em decorrência da falta de evidências acerca da transmissão vertical, a recomendação dos autores foi não amamentar (FILHO; SANTOS; JUNIOR, 2020).

Além das preocupações advindas pelo processo gravídico-puerperal, as incertezas diante da pandemia intensificam problemas relacionados à saúde mental, sobretudo pensamentos negativos perante o processo de AM, medo e incertezas sobre os cuidados dela e do bebê frente à pandemia, mostrando-se relevante o papel de consultores em amamentação e profissionais especializados, a fim de fornecer suporte às lactantes por meio de atendimentos por teleconsultas e ações educativas.

Ademais, evidenciou-se que as lactantes estavam praticando o distanciamento social, restrição de visitas e adotando medidas mais cautelosas de higiene pessoal, assim como do lar. 


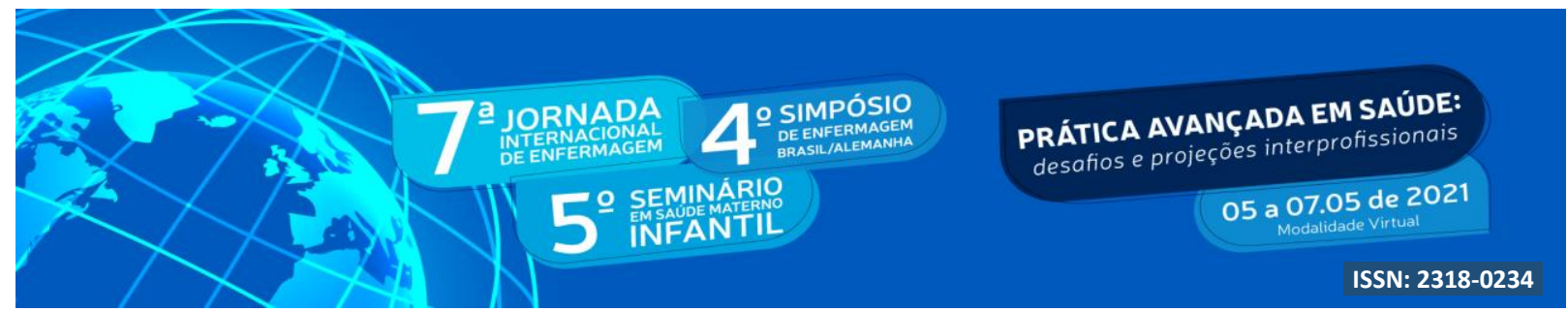

Embora necessário o menor contato com outros membros familiares, este impactou na diminuição da rede de apoio presencial à puérpera, o qual foi minimizado com o aconselhamento em saúde, incentivo ao autocuidado, empatia e respeito às individualidades das mães (LÓPEZ et al., 2020; LIMA et al., 2020; CALI; KREDS; CARVALHO, 2020).

No tocante aos cuidados de mães lactantes infectadas pela COVID-19, além de serem instruídas sobre as medidas de proteção do bebê, deve ser orientada a cuidar de sua alimentação, hidratação, fazer repouso e receber suporte multiprofissional em caso de agravamento dos sintomas. Somado a isso, os RN devem possuir medidas antropométricas adequadas no pós-parto, ausência de insuficiências respiratórias e controle dos sinais e sintomas, para que se necessário efetue a intervenção e diagnóstico precoce, evitando assim manifestações graves que podem evoluir a óbito (MASCARENHAS et al., 2020). Nesse sentido, Contreras et al. (2020) aborda que o conhecimento dos profissionais para ações diagnósticas e preventivas nas primeiras horas de vida, bem como o aconselhamento para amamentação, promovendo acomodação conjunta e contato pele a pele caso não existam contra indicações, sendo recomendada na região das Américas durante a pandemia.

Em casos que requeiram assistência hospitalar por agravamento ou intercorrências na saúde materna, recomenda-se a realização do alojamento conjunto, em casos assintomáticos para que o bebê não seja separado da mãe (DANTAS et al., 2020). Todavia, essa escolha requer cuidados preventivos, como distanciamento de dois metros entre o berço e o leito materno. Somado a isso, a amamentação ou extração do leite materno para oferecer ao bebê, com auxílio profissional em uma colher ou xícara, configura-se uma alternativa para as puérperas que desejam evitar o contato direto com o RN ou em casos de que as condições clínicas da mulher não propiciam o alojamento conjunto (DANTAS et al., 2020; CALI; KREDS; CARVALHO, 2020; MARCHIORI et al., 2020).

Além disso, compete ao profissional orientar a mãe sobre a importância de extrair de quatro a seis vezes ao dia seu leite, para assim manter a produção. No entanto, em casos em que esta não possa realizar a ordenha, recomenda-se a solicitação de Bancos de Leite Humano $(\mathrm{BLH})$, pois o uso de fórmula infantil pode ocasionar alergia à proteína do leite de vaca, além de possuir alto custo (DANTAS et al., 2020; CALI; KREDS; CARVALHO, 2020; MARCHIORI et al., 2020). Nesse contexto, o acolhimento do companheiro ou acompanhante 


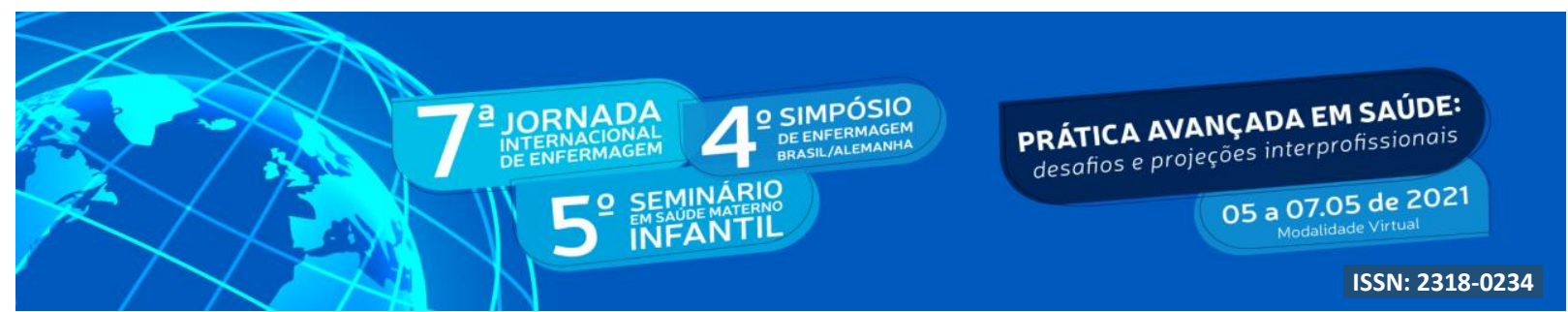

mostra-se fundamental no processo de nutrição e afeto, devendo sua participação no cuidado ser incentivada.

O BLH consiste em um aliado da política pública do AM, uma vez que, especialmente durante a pandemia, essa prática tem demandado cuidados diferenciados e, a inexistência de estudos que comprovem a transmissão vertical durante a gravidez. Por isso, foram necessárias organizações em tais serviços a fim de preservar a saúde da mulher, do RN, de familiares e de profissionais da saúde. Ainda, Marchiori et al. (2020), cita algumas estratégias que foram utilizadas pela equipe de enfermagem no cenário de pandemia em BLHs do Rio de Janeiro e Espírito Santo, bem como a utilização de meios digitais, intensificação do atendimento telefônico, a fim de garantir o distanciamento social no que tange às demandas de curto prazo e, em caso de emergência.

Percebe-se a necessidade do fortalecimento e expansão de pesquisas acerca da temática, a fim de aumentar as evidências e fornecer aos profissionais informações para uma assistência segura e de qualidade, mostrando os impactos da não realização do AM e a transmissão do SARS-CoV-2. À vista disso, relativo à enfermagem, configura-se essencial a busca de conhecimentos e atualização sobre a temática, uma vez que estes realizam orientações constantes à mãe e família do RN e, gerenciam serviços de saúde, por exemplo, BLHs (MARCHIORI et al., 2020). Ainda, Contreras et al (2020) corrobora a necessidade de conhecimento das temáticas pelos profissionais, que devem realizar buscas por evidências atualizadas, devido às particularidades da doença e das lacunas na realização de estudos.

\section{CONCLUSÃO}

Com a análise dos estudos pode-se observar diferentes percepções entre os países sobre o processo de amamentar durante a pandemia de COVID-19. Em relação ao contexto brasileiro, os profissionais da saúde, sobretudo o(a) enfermeiro(a), devem incentivar o AM, desde que seja benéfico tanto para a mulher quanto para o bebê, tendo em vista sua riqueza nutricional e o contato afetivo que esse momento proporciona.

Ainda, evidenciou-se que os cuidados de enfermagem demandam conhecimento e atualizações acerca da temática, para garantir uma assistência segura e de qualidade, seguindo 


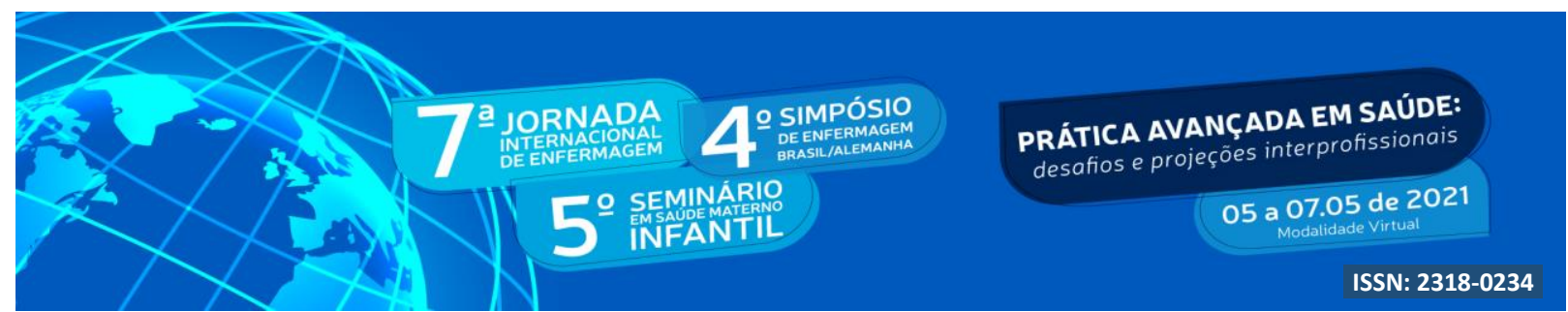

os protocolos vigentes e promovendo atenção integral à saúde. Além disso, por se tratar de profissionais que desempenham, muitas vezes, papéis de gestão, a atuação é imprescindível no aconselhamento ao AM a reorganização dos serviços de saúde. Como os BLH, a fim de garantir que a prática se mantenha, por meio de ferramentas tecnológicas de comunicação que propiciem a manutenção da rede de apoio e a segurança materno-infantil.

\section{REFERÊNCIAS}

BAGLÁN-BOBADILLA, Norma Victoria. Promoción de la lactancia materna en tiempos de COVID-19. Revista de Información Científica, Cuba, v. 99, n. 5, p. 410-411, set/out. 2020. Disponível em: http://scielo.sld.cu/scielo.php?script=sci_arttext\&pid=S102899332020000500410.

BRASIL. Ministério da Saúde. Governo Federal. Coronavírus. Covid-19. O que é Covid, 2020. Brasília, DF: Ministério da Saúde, 2020a. Disponível em:

https://coronavirus.saude.gov.br/.

BRASIL. Ministério da Saúde. Governo Federal: Secretaria de Atenção Primária à Saúde. Coronavírus: Conheça as orientações para amamentação. 20 de março de 2020c. Brasília, DF: Ministério da Saúde, 2020c. Disponível em: 〈https://aps.saude.gov.br/noticia/7717>.

BRASIL. Ministério da Saúde. Instituto Nacional de Saúde da Mulher, da Criança e do Adolescente. Fundação Oswaldo Cruz. Covid-19 e Saúde da Criança e do Adolescente. Rio de Janeiro: Ministério da Saúde, 2020b. Disponível em:

http://www.iff.fiocruz.br/pdf/covid19_saude_crianca_adolescente.pdf.

BRASIL. Ministério da Saúde. NOTA TÉCNICA Nº/2020- DAPES/SAPS/MS. Brasília DF, 2020d. Disponível em:https://docs.bvsalud.org/biblioref/2020/05/1096466/notatecnicaam amentacao92020dapessapsms03abr2020covid-19.pdf.

CALI, V. M. L. T.; KREDS, V. L. J.; CARVALHO, W. B. de. Guidance on breastfeeding during the Covid-19 pandemic. Revista da Associação Médica Brasileira, São Paulo, BR, v. 66, n. 4, p. 541-546, 15 jul. 2020. Disponível em:

https://www.scielo.br/scielo.php?script=sci_arttext\&pid=S0104-42302020000400541.

CONTRERAS, D. M. et al. Conocimentos sobre COVID-19 en Recién Nacidos y Lactancia Materna en Trabajadores de la Salud. Medicina Interna. 2020, v. 36, n. 2, p. 98-104. Disponível em: https://www.svmi.web.ve/ojs/index.php/medint/article/view/554/542.

DANTAS, A. C. et al. Refletindo sobre o contexto da amamentação durante a pandemia da COVID-19. Enfermagem em foco, Brasília, DF, v. 11, n. 2, p. 236-239, 1 dez. 2020. Disponível em: 


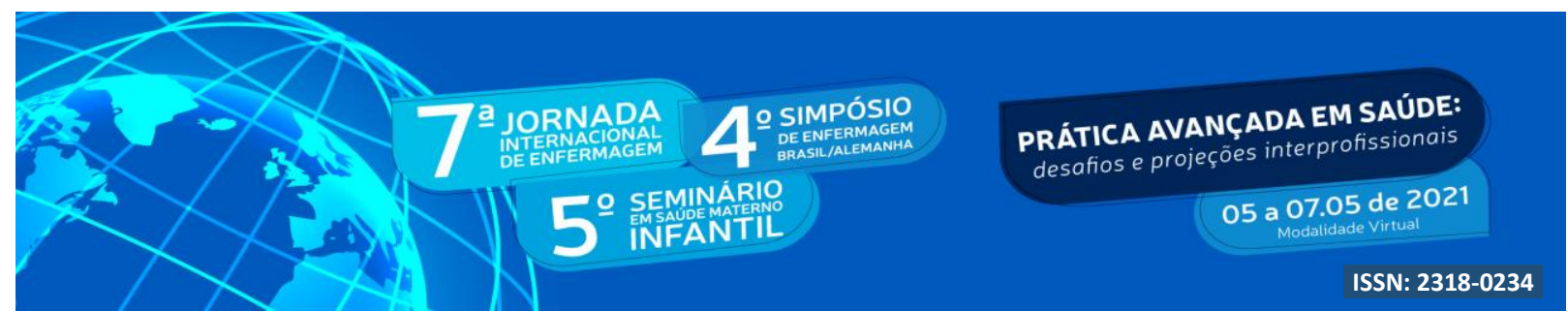

http://revista.cofen.gov.br/index.php/enfermagem/article/view/3616/1012.

FILHO, P. R. M.; SANTOS, V. S.; JUNIOR, H. P. S. To breastfeed or not to breastfeed? Lack of evidence on the presence of SARS-CoV-2 in breastmilk of pregnant women with COVID-19. Rev Pan American Journal of Public Health. 2020, v. 44, p. 1-5. Disponível em: https://iris.paho.org/bitstream/handle/10665.2/52038/v44e592020.pdf?sequence=5.

LIMA, A. C. M. A. C. C. et al. Consultoria em amamentação durante a pandemia

COVID-19: relato de experiência. Escola Anna Nery, Rio de Janeiro, BR, p. 1-6, ago. 2020. Disponível em: https://www.scielo.br/scielo.php?script=sci_arttext\&pid=S141481452020000500602 .

LÓPEZ O., Paulina et al. Revisión de los riesgos maternos y perinatales en tiempos de COVID-19: desafíos para el rol de la Matronería. Revista Chilena de Obstetricia y Ginecología, Santiago, Chile, v. 85, p. 131-147, 1 set. 2020. Disponível em: https://scielo.conicyt.cl/scielo.php?script=sci_arttext\&pid=S0717-75262020000700018.

MARCHIORI, G. R. S. et al. Nursing actions in human milk banks in times of COVID-19. Revista Brasileira de Enfermagem. 2020, v. 73, supl. 2, p. 1-9. Disponível em: http://www.revenf.bvs.br/scielo.php?script=sci_arttext\&pid=S0034-71672020000900155

MASCARENHAS, V. H. A. et al. Care recommendations for parturient and postpartum women and newborns during the COVID-19 pandemic: a scoping review. Revista LatinoAmericana de Enfermagem, [S. 1.], v. 28, p. 1-12, 1 ago. 2020. Disponível em: http://www.revenf.bvs.br/scielo.php?script=sci_arttext\&pid=S0104-11692020000100609

MOCELIN, Helaine Jacinta Salvador; PRIMO, Cândida Caniçali; LAIGNIER, Mariana Rabello. Panorama sobre as recomendações para amamentação em tempos de COVID19. J. Hum. Growth Dev. (Impr.), Universidade Federal do Espírito Santo - Brasil, v. 30, n. 3, dez. 2020. Pediatria/Saúde Pública, p. 335-343. Disponível em:

http://pepsic.bvsalud.org/pdf/rbcdh/v30n3/pt_02.pdf.

PRATA, A. P. et al. Relactação: promover a amamentação em mães separadas de seus filhos devido ao COVID-19. Enfermagem em foco, Brasília, DF, v. 11, n. 2, p. 240-245, 2020. Disponível em: http://revista.cofen.gov.br/index.php/enfermagem/article/view/ $3736 / 1013$.

UNIVERSIDADE FEDERAL DO AMAZONAS. Mortalidade por Covid entre bebês com menos de um ano é dez vezes maior que crianças e jovens até 19 anos. Acrítica, 2021.

Disponível em: $<$ https://www.acritica.com/channels/coronavirus/news/mortalidade-por-covidentre-bebes-com-menos-de-um-ano-e-dez-vezes-maior-que-criancas-e-jovens-ate-19-anos > 